\title{
Multi-Disciplinary Experience - A Key Learning Experience in Effective Education for Sustainable Development
}

\author{
Mahendra Gooroochurn ${ }^{1, *}$, Bhoomitra Toolsy ${ }^{2}$ \\ ${ }^{1,2}$ Mechanical and Production Engineering Department, Faculty of Engineering, University of Mauritius, 80837 \\ Reduit, Mauritius \\ *corresponding author: m.gooroochurn@uom.ac.mu
}

\section{Article Info}

Received:
15 March 2021
Accepted:
25 May 2021
Published:
1 June 2021
Dol:
https://doi.org/10.14710/j
sp. 2021.11206

\begin{abstract}
The key role of education for achieving sustainable development has been well recognized around the world and used as a powerful lever for transforming economies based on sound principles. Indeed universities are prime institutions which have the essential role to impart requisite knowledge and skills to learners so that they can stand to the challenges in their respective professions, which means universities have had to bring radical changes to their curricula over the past decade to integrate sustainability principles as well as come up with new programmes centered on sustainability. However, the multi-disciplinary nature of sustainability projects as they occur in real-life has meant that the education curricula cannot be developed in isolation for a given programme of studies, but need to have linkages and crossover with other disciplines to provide a platform for learners to nurture this all-important skill. The University of Mauritius has aligned this key ingredient of education for sustainable development (ESD) with the accreditation framework for engineers provided by the Washington Accord through its graduate attributes, specifically Graduate Attribute 8 which includes multidisciplinary work within the range statement. This paper describes the methods adopted to implement this cross-linking between programmes from different disciplines effectively.
\end{abstract}

\section{Keyword:}

Education for Sustainable Develop, Graduate Attributes, Engineering accreditation, Multi-disciplinarity

\section{Introduction: Education for Sustainable Development}

Under the sustainability development goal is quality education. According to UNEP, by 2030 , there is the need to ensure that all learners acquire the knowledge and skills needed to promote sustainable development, including, among others, through education for sustainable development and sustainable lifestyles, human rights, gender equality, promotion of a culture of peace and non-violence, global citizenship and appreciation of cultural diversity and of culture's contribution to sustainable development. 
The knowledge of sustainable development is multidisciplinary in its nature and is covered by various bodies of sciences. However, as noted by Sinakou et al. [1], academics do not consider the sustainability in a holistic way, with a tendency towards the social and economic aspects, and they discuss the implication of their findings on the need for research and teacher training. In recent years and the UN SDGs, 'sustainable development' has become a central theme for discussion at governmental levels, between governments, civil society and between government and private sector. This has triggered new requirements for pedagogy and has also created new challenges to institutions to review their approaches to education. Indeed Bento et al. [2] support the idea in their study on the need for responsible management in Higher Education Institutes (HEIs) via the integration of sustainability and ethics.

The current major sustainability problems, such as global climate change, water and air quality, biodiversity loss, sustainable world energy use and disease emergence, reemergence and spread are multifaceted and entangled with social, scientific, engineering and political dimensions, so that they cannot be solved within the confines of a single STEM discipline. Universities have been faced with the challenge to balance between the competing demands of breadth and depth of subject matter, generally relying on a discipline-based learning model. Hoveskog et al. [3] engaged students in an experiential workshop aimed at developing a business model innovation for a biogas production cooperative of farmer-members in southern Sweden. The outcomes of the workshop show the unique opportunity such collaborative effort has on application of knowledge to practice, suggesting that Education for Flourishing can be used to further Education for Sustainable Development. Nousheen et al. [4] showed through their research survey that education for sustainable development had a definite positive influence towards sustainable development compared to the students-teacher group which did not take such training, reinforcing the unique role universities have to imbibe sustainability in their graduate. As discussed by Annan-Diab et al. [5], the very basis of the UN SDGs is the linking of various disciplines to achieve a well-thought and comprehensive approach, as opposed to a disjointed, segmented paradigm, despite dealing with the disciplines involved.

Sustainability are complex issues that require systems thinking approaches and it is essential to build in the capacity of graduates with a diverse set of diverse disciplines, but containing some depth in the subject matter so that they can analyse sustainability issues in a scientific manner. This new educational challenge can be addressed in one of two ways: (1) through an interdisciplinary approach, concepts from different disciplines can be integrated to generate new ways of thinking. Participants must become fluent in the participating disciplines to create new approaches. (2) Through a multidisciplinary approach, the distinct perspectives and concepts of each discipline can be used to tackle particular portions of a complex problem; fluency in all the participating disciplines, however, is no longer required.

\section{Accreditation process of engineering degree programme and graduate attributes}

\subsection{Accreditation process}

The accreditation process for engineering programmes is geared towards ensuring the graduates meet specific competences exclusively for qualifying to be considered eligible to pursue further training to gain professional engineer status. These competences, formerly known as Exit Level Outcomes (ELOs), are currently termed as graduate attributes 
spread across ten attributes as summarized in Table 1. Each graduate attribute has a range statement described in a guidance document, for example [6] from the Engineering Council of South Africa.

Table 1. Graduate Attributes

\begin{tabular}{cl}
\hline Graduate Attribute & \multicolumn{1}{c}{ Description } \\
\hline 1 & Problem Solving \\
2 & Application of scientific and engineering knowledge \\
3 & Engineering Design \\
4 & Investigations, experiments and data analysis \\
5 & Engineering methods, skills and tools, including Information \\
6 & Technology \\
7 & Professional and technical communication \\
8 & Individual, Team and Multidisciplinary Working \\
9 & Independent Learning Ability \\
10 & Engineering Professionalism \\
\hline
\end{tabular}

Of relevance for the purpose of this article is graduate attribute 8, namely Individual, Team and Multidisciplinary working, specifically the multi-disciplinary dimension if this attribute, which is described in further details next.

\subsection{Graduare Attribute 8: Multi-disciplinarity}

The description and range statement for this graduate attribute as described in [6] is as follows:

Demonstrate knowledge and understanding of engineering management principles and apply these to one's own work, as a member and leader in a technical team and to manage projects.

\section{Range Statement:}

1. The ability to manage a project should be demonstrated in the form of the project indicated in Graduate Attribute 3 (Engineering Design)

2. Tasks are discipline specific and within the technical competence of the graduate.

3. Projects could include: laboratories, business plans, design, etc.

4. Management principles include:

4.1 Planning: set objectives, select strategies, implement strategies and review achievement;

4.2 Organising: set operational model, identify and assign tasks, identify inputs, delegate responsibility and authority;

4.3 Leading: give directions, set example, communicate, motivate;

4.4 Controlling: monitor performance, check against standards, identify variations and take remedial action.

Therefore, as part of the module assessing this specific graduate attribute, engineering a given student is placed in a team composed of students from other disciplines in engineering and from fundamentally different background. The former could take the 
form of a mechanical engineering student working with electrical or civil engineering working on different aspects of a project, yet on a part within their technical expertise, while the latter can lead to a management or economics/finance student working with engineering students. The aim of the whole team project work is to integrate the vital skills from these different disciplines around a given goal or problem to encourage the multidisciplinary consideration which has become key in sustainability projects, and for sustainability to stand any chance to see light. In the current circumstances, the students work in groups with members from another engineering discipline, and it would

\section{Case studies - Multi-Disciplinarity in Action}

\subsection{Case study 1: Intergrated Design for Sustainability in the Built Enviroment}

The first case study being presented which has a direct bearing on multi-disciplinarity and relying heavily on integrating the competences of team members from fundamentally different background is achieving sustainability in the built environment. Indeed, after the industrial revolution with the emergence of active building energy systems, the divergence from an integrated thinking has led to the built environment having unprecedented negative impact on the environment, which is why rating systems like the UI Greenmetric [7], LEED [8] and BREEAM [9] have laid heavy emphasis on buildings. Green building rating systems such as LEED and BREEAM give credit to those projects which implement an integrated approach at the outset, where the different team members, including the client, architect, project manager, structural engineer, mechanical, electrical and plumbing consultant (MEP), quantity surveyors, landscape architect, and preferably potential contractors collaborate in design charrettes to find scopes for synergy. Such exercises have been evidenced to lead to huge savings in energy and resources in general, during operations and even cost savings in the project initial budget due to reduced size of equipment and plants.

For example, the collaboration between the MEP engineers and the architect can lead to informed decisions on the building envelope (fabric and glazing) which can subsequently lead to enhanced use of natural resources in the form of natural ventilation and daylight, decreased cooling load and artificial lighting requirements, which can reduce capital expenditures on equipment as well as reduce operational costs with a reduced carbon footprint. The added advantage of providing an internal environment where occupants feel and perform better, where students have been evidenced to achieve higher grades is of paramount interest for human resources management.

Another design scenario where this integrated thinking can enhance value and sustainability is evidenced by the design and choice of plants for the landscaping of the project which directly impact the water requirement, hence size of retention tanks, pipe works, pump sets etc. This further cascades to reduced potable water need on-site, which when combined with harvesting of rainwater as a natural resource available at the project site, can considerably help in managing stormwater run-off during periods of high rainfall intensity. Therefore whether rain is considered as a harvested resource (desired) or as runoff (desired) hinges on the design approach taken for the project and how we decide to use it. To provide such synergy, the structural, MEP, landscape architect and the architect among others need to join hands, as opposed to each professional working in a siloed mode. This is a concrete example where each discipline is represented in engineering the solution, but yet no synergy is achieved due to lack of joint design efforts. Such design optimization 
occurs in a multifarious aspects of a building project, and the project team which harnesses them in an intelligent way achieves proper sustainable design.

\subsection{Case study 2: A multi-disciplinary approach to enhancing sustainability of the supply chain of fresh fruits and vegetables (FFV) in Mauritius}

Agriculture contributes to $3.4 \%$ of GDP and $8.3 \%$ of employment in Mauritius. Although Mauritius is considered as a net-food importing country by World Trade Organisation, the small-scale agriculture sector is vital to sustain the production of some 115,000 tonnes of food crops annually. Some 9,000 small-scale farmers are involved in vegetables and fruit production with limited capacity in marketing group initiatives. There is an increasing demand in Mauritius for food with higher standards. With the growing concern for safe and healthy foods, improving farmers/workers' health and safety, and reducing environmental impacts, there is a need to address the inherent risks related to fresh fruits and vegetables (FFV) production in Mauritius.

The Government of Mauritius has developed and implemented a voluntary Green Agricultural Certification and eco-labelling scheme known as MauriGAP to promote the supply of safe and high quality locally produced fresh products while promoting more sustainable crop production. It should be noted that MauriGAP provides a phased transition to organic farming. However, to promote sustainable food supply, the government initiative needed to be supported by a greener supply chain and an enhanced demand for sustainable local products.

It was vital to study the complexity of the situation and the analysis would be inadequate if insufficient to analyse with a single discipline. Competencies in supply chain management, food safety, life cycle analysis, procurement management, green marketing, customer perceptions and economics were allowed a systematic approach of supply processes, the demand pull and the logistics between. The demand analysis was essentially focused on identifying customer preferences and expectations for sustainable products, their level understanding of sustainable supply chain of FFV, their motivations for purchasing decisions and barriers to sustainability choices. It also assessed the procurement practices in both hotels and retailers and identified training needs of these sectors and the expectations of procurement managers.

The adopted methodology included secondary data based on past work conducted on past and future trends, consumer surveys, expert judgement, expert interviews and survey of procurement managers. The status of the supply chain of local Fresh Fruits and Vegetables (FFV) in Mauritius was analysed to identify challenges for implementing sustainability concepts and tools which could become key push factors for influencing sustainable supply of FFV and opportunity areas for value addition. The supply side mapping was essentially conducted using the hotspot analysis framework to identify sustainability priorities along the entire life cycle of FFV and categorised into environmental, social and economic hotspots (based on the concept of 3E's of sustainability). The hotspot analysis of the supply chain of local FFV (from cultivation to distribution) identified the sustainability risks and opportunities, which needed to be addressed. The mapping study resided on the definition of a typical farm representative of small growers using the conventional open field. The study identified the priority environmental, social and economic areas for improvement and opportunities for the project to address in order to enhance the supply chain of FFV with respect to the needs of retailers and hotels. The prices in the wet markets and retail supermarkets were also analysed to identify 
The supply side mapping, the analysis of demand side and hotspot analysis identified the training needs of different stakeholders in the whole supply chain. The output of the multi-disciplinary analysis served as basis for development of tailor-made training packages for building the capacity of procurement / quality / marketing managers on how to develop sustainable procurement, identification of areas for raising awareness on sustainable agriculture and reinforcing communication. The demand side mapping also provides valuable feedback for the orientation of the pilot implementation projects and developing sustainable marketing initiatives, which would differentiate certified FFV from those produced by conventional methods.

To attract the managers from both retail and hotel sectors, a concept note on capacity building was developed and a strategic invitation was produced to get the collaboration of the concerned sectors. The capacity building had the following objectives to:

- enhance the participants' understanding of MauriGAP and how their hotel / retail processes can be enhanced to influence the adoption of MauriGAP by planters and ensuring traceability of MauriGAP-certified products towards hotel customers

- enhance the participants' understanding of the environment, social and economic hotspots in the supply chain of FFV and the needs to improvement towards sustainability

- develop the capacity of participants on how to use the hotspots methodology to evaluate sustainability issues in the life cycle of FFV, to identify priority areas of action along the value chain of FFV and to foster step-by-step improvements of the FFV supply chain towards more sustainability,

- develop the capacity of participants to adopt sustainable supply chain management practices in terms of green procurement policy, procurement guidelines tailored to the different sectors, supplier selection criteria, contractual agreements with suppliers for long-term collaboration and traceability of MauriGAP-certified FFV.

- develop the capacity of participants to enhance their marketing practices through the development of relevant strategies, approaches, campaign concepts and marketing actions to promote MauriGAP-certified FFV to their customers and engage customers for local sustainable food.

Finally, a sustainable procurement guideline was produced, so that hoteliers and retailers, could incorporate or merge it with their existing in-house guidelines. Sustainable supply chain management was implemented by focusing on the critical points along the value-chain, so-called hotspots, taking into consideration the tropical climate in an insular context.

Creating a sustained demand for MauriGAP FFV is ultimately dependent on customer interaction, satisfaction and repeat sales. For retailers, a marketing support package was created, indicated which levers could be used for customer interaction. Indeed, retailers and their stores were capacitated to engage in marketing actions through communication messages and in-store promotion ideas, the objective being a long-term recognition of MauriGAP as label for healthier and safer produce. For hoteliers, the exercise was more complex, since hotel guests stay for a limited duration and moreover, they receive little visibility as to the sourcing of food produce. MauriGAP nonetheless offers hotels the possibility of innovating on the marketing side, by offering FFV cooking classes, providing greater information about the exotic FFV or even visits to MauriGAP farms. 
The project brought a considerable change in procurement practices based on TQM principles, whereby the collaboration between retailers / hotels and planters were viewed from a partnership for growth perspective. The procurement methods were enhanced from reactive to a proactive one, which is typical of total quality management. This major change identified the need for new competencies in procurement, especially sustainable agricultural principles, standards and practices. In one retail company, a cell of technical experts (including 4 young agricultural science graduates) were recruited to work with the suppliers in their fields to implement MauriGAP and develop the administrative capability to do record-keeping which is fundamental for the certification process. Close linkage were maintained with the planters with respect to clarification/implementation of the standards control points. Awareness raising and capacity development was conducted on MauriGAP standards to explain benefits to the environment, planters, consumers and business and demonstrate the economic feasibility of farm certification. Following the capacity building, innovative collaboration workshops were organised between planters and retailers to discuss areas for new business opportunities, win-win collaboration and how to create the demand for MauriGAP-certified fresh fruits and vegetables.

\section{Conclusion}

With the ever more complex interaction between phenomena affecting the systems we engineer, and the need to have a close accountability of the design factors on the performance and hence on the environmental impact of our actions, the need for multidisciplinary work has never been more important. As demonstrated by the case studies presented in this article, university graduates will be required to work in multi-disciplinary teams with members from fundamentally different domains to their own, and this needs to be accounted for and taught in curricula geared towards education for sustainable development. Realizing this need for graduates to be ready to apply sustainability science within their own discipline and in collaboration with other professionals, the University of Mauritius has embarked on integrating sustainability topics throughout its curricula and through the accreditation process of its engineering degree programmes, specifically the graduate attribute 8 , has provided a learning environment where this essential multidisciplinary work can take place.

\section{References}

1. Eleni Sinakou, Jelle Boeve-de Pauw, Maarten Goossens, Peter Van Petegem, Academics in the field of Education for Sustainable Development: Their conceptions of sustainable development, Journal of Cleaner Production, Volume 184, 2018, Pages 321-332, ISSN 0959-6526.

2. Aline Bento Ambrosio Avelar, Keilla Dayane da Silva-Oliveira, Raquel da Silva Pereira, Education for advancing the implementation of the Sustainable Development Goals: A systematic approach, The International Journal of Management Education, Volume 17, Issue 3, 2019, 100322, ISSN 1472-8117.

3. Maya Hoveskog, Fawzi Halila, Marie Mattsson, Antony Upward, Niklas Karlsson, Education for Sustainable Development: Business modelling for flourishing, Journal of Cleaner Production, Volume 172, 2018, Pages 4383-4396, ISSN 0959-6526.

4. Ayesha Nousheen, Sajid Ali Yousuf Zai, Muhammad Waseem, Shafqat Ali Khan, Education for sustainable development (ESD): Effects of sustainability education on preservice teachers' attitude towards sustainable development (SD), Journal of Cleaner 
Production, Volume 250, 2020, 119537, ISSN 0959-6526.

5. Fatima Annan-Diab, Carolina Molinari, Interdisciplinarity: Practical approach to advancing education for sustainability and for the Sustainable Development Goals, The International Journal of Management Education, Volume 15, Issue 2, Part B, 2017, Pages 73-83, ISSN 1472-8117.

6. Engineering Council of South Africa, Standards and Procedures System.

7. UI GreenMetric World University Rankings, available online at http://greenmetric.ui.ac.id.

8. United States Green Building Council, Leader in Energy and Environment Design (LEED) .

9. Building Research Establishment, Building Research Establishment Environmental Assessment Method (BREEAM 